\title{
The volume of general surgery emergency cases in a government hospital during the COVID -19 pandemic and two other periods: A comparative study
}

Ibrahim abu shakra

Galilee Medical Center https://orcid.org/0000-0002-2275-0705

Maxim Bez

Galilee Medical Center

Samer Ganam

Galilee Medical Center

Rula Francis

Galilee Medical Center

Amir Muati

Galilee Medical Center

Amitai Bickel

Galilee Medical Center

Fahed Merei

Galilee Medical Center

\section{Ziv Talmi}

Galilee Medical Center

Khatib Kamal

Galilee Medical Center

Eli Kakiashvili ( $\nabla$ elik@gmc.gov.il )

Galilee Medical Center

Research article

Keywords: COVID-19, SARS-CoV-2, Emergency Surgery, General Surgery

Posted Date: August 2nd, 2020

DOI: https://doi.org/10.21203/rs.3.rs-49541/v1

License: (c) (1) This work is licensed under a Creative Commons Attribution 4.0 International License.

Read Full License 
Page $2 / 12$ 


\section{Abstract \\ Objective}

We compared characteristics of patients admitted to a northern Israeli hospital with common surgical complaints during three periods: the lockdown due to the COVID-19 outbreak, the Second Lebanon War in 2006 , and a regular period.

\section{Background}

During March and April 2020, reductions in non-COVID-19 hospital admissions were observed around the world. Elective surgeries, visits with general practitioners, and diagnoses of medical emergencies were consequently delayed.

\section{Methods}

Demographic, medical, laboratory, imaging, intraoperative, and pathological data were collected from electronic medical files of patients who received emergency treatment at the surgery department of a single hospital in northern Israel. We compared characteristics of patients who were admitted with various conditions during three periods.

\section{Results}

Patients' mean age and most of the clinical parameters assessed were similar between the periods. However, pain was reportedly higher during the COVID-19 than the control period (8.7 vs. 6.4 on a 10-point visual analog scale, $P<0.0001)$. During the COVID-19 outbreak, the Second Lebanon War, and the regular period, the mean numbers of patients admitted daily were $1.4,4.4$, and 3.0 , respectively. The respective mean times from the onset of symptoms until admission were 3,1 , and 1.5 days, $P<0.001$. The respective proportions of surgical interventions for appendiceal disease were $95 \%, 96 \%$, and $69 \% ; P=$ 0.03 .

\section{Conclusion}

Compared to a routine period, patients during the COVID-19 outbreak waited longer before turning to hospitalization, and reported more pain at arrival. Patients during both emergency periods were more often treated surgically than non-operatively.

\section{Introduction}


During the months March and April 2020, countries around the world enforced social containment rules, including public commute restrictions and the closure of "non-essential" public places, as means to reduce the spread of the COVID-19 pandemic. ${ }^{1}$ Substantial reductions in non-COVID-19 hospital admissions were consequently observed, possibly reflecting reluctance to seek medical care due to the high risk of infection from the novel virus. ${ }^{2}$ During this period, many elective surgeries and visits with general practitioners were delayed and some health checkups were avoided altogether. ${ }^{3}$ This reality led to considerable delays in diagnoses of medical emergencies ${ }^{4}$, even when hospitals allocated necessary resources to continue non-COVID related medical activities in emergency departments and admitted patients with any medical emergency.

In this study, we analyzed the characteristics of patients who were admitted to a northern Israeli hospital with common surgical complaints during a state of emergency due to the COVID-19 outbreak. The characteristics of the patients were compared to a previous state of emergency in Israel, during the Second Lebanon War in 2006, and to a regular period in the hospital during the previous year. During the Second Lebanon War, the northern area of Israel, the region where our hospital is located was exposed to missile attacks on a daily basis.

\section{Methods}

This single center retrospective study included patients who were admitted to Galilee Medical Center, Israel, with surgical emergencies, during three periods. The first period is during the COVID-19 pandemic outbreak, when a countrywide lockdown was enforced from March 1, 2020 to April 19, 2020 (50 days). The second period refers to the Second Lebanon war, between July 12, 2006 and August 14, 2006 (34 days). Both these periods were defined as states of emergency by the Israeli government. For the establishment of a control group, the third period was defined as August 1, 2019 to December 31, 2019 (153 days). The study was approved by the institutional Helsinki Committee.

\section{Data collection}

Data were collected from electronic medical files of all the patients who received emergency treatment at the surgery department. The files were reviewed for demographic data (gender, age) medical data (chronic comorbidities, associated illnesses, the elapsed time since the start of symptoms, the surgical approach, the type and duration of treatment, hospital stay, perioperative complications), and laboratory, pathological, imaging analysis, and intraoperative findings. To investigate possible differences in clinical presentation and treatment between the state of emergency periods and the control period, we compared characteristics of patients admitted to the surgical department with the following conditions: intestinal diseases (intestinal obstruction, volvulus, intestinal perforation, diverticulitis, and mesenteric ischemia), diseases of the appendix (appendicitis and appendicular abscess), biliary diseases (acute cholecystitis, cholangitis, and pancreatitis), gastric and duodenal ulcers and perforations, abscesses (perineal, pilonidal, and gluteal), gastrointestinal bleeding, and incarcerated or strangulated hernias (including inguinal, femoral, ventral, and umbilical hernias). 


\section{Statistical analysis}

Means, standard deviations, and medians were calculated for all the variables examined. Continuous variables were tested for normal distribution using the Kolmogory-Smirnov test, and groups were compared using ANOVA or the Kruskal-Wallis test. The Chi squared test was used to compare categorical variables between groups. All statistical analyses were done using SPSS ver. 25.

\section{Results}

This study included a total of 677 patients admitted to the surgical department; 71 during the COVID-19 outbreak, 149 during the 2006 Second Lebanon War, and 457 during the control period. The mean numbers of patients per day for the respective periods were 1.4, 4.4, and 3.0. Most patients were admitted due to biliary disease, abscess, intestinal disease, or acute appendicitis: $28.4 \%, 24.1 \%, 21.0 \%$, and $15.2 \%$ respectively (Table 1$)$.

Table 1

Reasons for presentation at the surgical department during three periods of time.

\begin{tabular}{|lllll|}
\hline & $\begin{array}{l}\text { Control }(\mathrm{n}= \\
\mathbf{4 5 7})\end{array}$ & $\begin{array}{l}\text { COVID-19 }(\mathrm{n}= \\
\mathbf{7 1})\end{array}$ & $\begin{array}{l}\text { Wartime }(\mathrm{n}= \\
\mathbf{1 4 9})\end{array}$ & $\begin{array}{l}\text { Total }(\mathrm{n}= \\
\mathbf{6 7 7})\end{array}$ \\
\hline $\begin{array}{l}\text { Gastrointestinal } \\
\text { bleeding }\end{array}$ & $19(4.1 \%)$ & $1(1.4 \%)$ & $6(4 \%)$ & $26(3.8 \%)$ \\
\hline Hernia & $14(3.0 \%)$ & $4(5.6 \%)$ & $18(12.0 \%)$ & $36(5.3 \%)$ \\
\hline Intestinal diseases & $105(22.9 \%)$ & $11(15.4 \%)$ & $26(17.4 \%)$ & $142(21.0 \%)$ \\
\hline Other diseases & $2(0.1 \%)$ & 0 & $6(4.0 \%)$ & $8(1.2 \%)$ \\
\hline Abscess & $116(25.3 \%)$ & $21(29.5 \%)$ & $26(17.4 \%)$ & $163(24.1 \%)$ \\
\hline Acute appendicitis & $55(12.0 \%)$ & $19(26.8 \%)$ & $29(19.5 \%)$ & $103(15.2 \%)$ \\
\hline Biliary diseases & $140(30.0 \%)$ & $13(18.0 \%)$ & $39(26.0 \%)$ & $192(28.4 \%)$ \\
\hline Perforation \& ulcer & $3(0.6 \%)$ & $2(2.8 \%)$ & $2(1.3 \%)$ & $7(1.0 \%)$ \\
\hline
\end{tabular}

The mean age of the patients did not differ between the periods of COVID-19, the Second Lebanon war, and the control groups $(48.9 \pm 22.2,51.9 \pm 20.7$, and $52.1 \pm 20.9$, respectively, $P=0.48$; Table 2$)$. During the COVID-19 period, the percentage of patients presenting at the surgical department with diabetes was lower and the percentage with COPD was higher than during the other periods examined. Clinical and laboratory variables did not differ between the groups including heart rate, mean arterial pressure, body temperature, white blood cell count (WBC) and C-reactive protein (CRP). However, pain, assessed by a 10point visual analog scale (VAS) was rated higher during the COVID-19 than during the control period (8.7 vs. $6.4, \mathrm{P}<0.0001)$; VAS data were not available for the 2006 Lebanon war group. The time from the onset of symptoms until admission at the surgical ward was longest during the COVID-19 period ( 3 days), 
and shortest during wartime ( 1 day), $\mathrm{P}<0.005$. In both state-of-emergency periods, $63 \%$ of the patients who were admitted received surgical treatment compared to only $36 \%$ in the control group $(P<0.001)$. 
Table 2

Demographic and clinical characteristics of patients who presented at the surgical department during three periods of time

\begin{tabular}{|c|c|c|c|c|}
\hline & $\begin{array}{l}\text { Control }(n= \\
457)\end{array}$ & $\begin{array}{l}\text { COVID-19 }(n= \\
71)\end{array}$ & $\begin{array}{l}\text { Wartime }(n= \\
149)\end{array}$ & $P$ value \\
\hline Age, years & $52.1 \pm 20.9$ & $48.9 \pm 22.2$ & $51.9 \pm 20.7$ & $P=0.48$ \\
\hline Gender & 257 (56\%) & $42(59 \%)$ & $92(62 \%)$ & $P=0.48$ \\
\hline Male & $200(44 \%)$ & $29(41 \%)$ & $57(38 \%)$ & \\
\hline \multicolumn{5}{|l|}{ Female } \\
\hline Heart failure & $58(13 \%)$ & $9(13 \%)$ & $29(20 \%)$ & $P=0.11$ \\
\hline Diabetes & $118(26 \%)$ & $5(7 \%)$ & $23(15 \%)$ & $P^{1,2}<0.01$ \\
\hline Kidney failure & $20(4 \%)$ & $7(10 \%)$ & $8(6 \%)$ & $P=0.15$ \\
\hline COPD & $43(9.2 \%)$ & $15(21.1 \%)$ & $23(15.8 \%)$ & $\mathrm{P}^{1,3}<0.05$ \\
\hline Asthma & $43(9.2 \%)$ & $8(11.3 \%)$ & $24(16.4 \%)$ & $P^{2}=0.02$ \\
\hline Hemoglobin & $13.2 \pm 2.2$ & $13.6 \pm 2.3$ & $13.1 \pm 2.1$ & $P=0.16$ \\
\hline White blood cell count & $11.4 \pm 3.7$ & $11.5 \pm 4.0$ & $11.85 \pm 4.30$ & $P=0.41$ \\
\hline CRP, median, IQR & $16.3[4.9-57.8]$ & $13.4[5.1-54.0]$ & $12.8 n=2$ & $P=0.58$ \\
\hline Body temperature & $36.8 \pm 0.37$ & $36.7 \pm 0.22$ & $36.8 \pm 0.59$ & $p=0.98$ \\
\hline $\mathrm{pH}$ & $7.37 \pm 0.06$ & $7.35 \pm 0.05$ & $7.51 n=1$ & $P=0.60$ \\
\hline Heart rate & $80.0 \pm 12.1$ & $80.1 \pm 8.9$ & $81.7 \pm 14.5$ & $P=0.65$ \\
\hline Pain, according to VAS & $6.39 \pm 1.17$ & $8.72 \pm 0.81$ & $\mathrm{~N} / \mathrm{A}$ & $P<0.001$ \\
\hline Creatinine & $0.99 \pm 0.64$ & $0.89 \pm 0.24$ & $1.06 \pm 0.42$ & $P=0.15$ \\
\hline BMI & $27.9 \pm 5.3$ & $27.7 \pm 4.5$ & $23.2 n=1$ & $P=0.60$ \\
\hline $\begin{array}{l}\text { Time from symptoms, } \\
\text { median, IQR }\end{array}$ & $1.5[1-3]$ & $3[1-4]$ & $1[0.42-1.5]$ & $P^{1,2,3}<0.001$ \\
\hline
\end{tabular}

$\mathrm{P} 1=$ Control vs. COVID-19 period

P2 = Control vs. Lebanon War period

P3 = COVID-10 vs. Lebanon War period

COPD, chronic obstructive pulmonary disease; CRP, C-reactive protein; VAS, visual analogue scale; $\mathrm{BMI}$, body mass index; IQR, interquartile range 


\begin{tabular}{|c|c|c|c|c|}
\hline & $\begin{array}{l}\text { Control }(n= \\
457)\end{array}$ & $\begin{array}{l}\text { COVID-19 }(n= \\
\text { 71) }\end{array}$ & $\begin{array}{l}\text { Wartime }(n= \\
\text { 149) }\end{array}$ & $P$ value \\
\hline Treatment & $166(36 \%)$ & $45(63 \%)$ & $93(63 \%)$ & $P^{1,2}<0.001$ \\
\hline Surgery & $9(2 \%)$ & 0 & $3(2 \%)$ & $P=1.00$ \\
\hline Invasive & $10(2 \%)$ & 0 & $4(3 \%)$ & $P=1.00$ \\
\hline $\begin{array}{l}\text { Invasive and conservative } \\
\text { Conservative }\end{array}$ & $\star 272(60 \%)$ & $\star 26(37 \%)$ & $48(32 \%)$ & $\begin{array}{l}* P^{1}= \\
0.0004\end{array}$ \\
\hline Conservative & & & & $\mathrm{P}^{2}<0.0001$ \\
\hline $\begin{array}{l}\text { Dementia (cognitive } \\
\text { status) }\end{array}$ & $23(5 \%)$ & $8(11.3 \%)$ & $10(6.7 \%)$ & $P=0.054$ \\
\hline \multicolumn{5}{|c|}{ P1 = Control vs. COVID-19 period } \\
\hline \multicolumn{5}{|c|}{ P2 = Control vs. Lebanon War period } \\
\hline \multicolumn{5}{|c|}{ P3 = COVID-10 vs. Lebanon War period } \\
\hline $\begin{array}{l}\text { COPD, chronic obstructive } \\
\text { BMI, body mass index; IQF }\end{array}$ & $\begin{array}{l}\text { monary dise } \\
\text { terquartile ra }\end{array}$ & , -reactive $p$ & VAS, visual & e scale; \\
\hline
\end{tabular}

Examining the surgical conditions separately, the differences observed between the groups in time from onset of symptoms until admission remained constant. For example, among patients with biliary disease, the median time until admission was 2 days in the COVID-19 group, 1 day in the 2006 Lebanon war group and 1.5 days in the control group $(P=0.021)$. The same pattern was observed among patients with appendiceal disease, with medians of 2 days, 0.5 days, and 1 day, respectively $(P<0.001)$.

The method of treatment of certain conditions differed between the time periods. For patients with appendiceal disease, more surgical interventions were performed during the state-of-emergency periods than during the control period (95\%, 96\%, and $69 \%$ during COVID-19, the Second Lebanon war and the control period, respectively; $P=0.03$ ). During the Second Lebanon war, $46 \%$ of the patients with biliary disease underwent surgical treatment compared to $4 \%$ during the control period and $8 \%$ during the COVID-19 period.

Eleven patients presented with intestinal diseases, during the COVID-19 pandemic compared to 26 during the Lebanon war and 105 patients during the control period; the respective average admissions per day were $0.22,0.76$., and 0.69. During the COVID-19 pandemic, patients with intestinal diseases were symptomatic for a longer period and arrived to the hospital within a median of 3 days compared to 0.75 days during the war and one day during the control period; $\mathrm{P}<0.05$. All the patients with gastrointestinal diseases were treated conservatively, with the exception of one patient who underwent surgery during the COVID 19 pandemic; no differences were observed between the periods. 


\section{Discussion}

This retrospective study aimed to examine the characteristics of patients treated in the surgical ward of The Galilee Medical Center during the COVID-19 outbreak. The focus was the time from onset of symptoms until treatment, and the treatment method. We compared patients treated during the COVID-19 outbreak to those treated during the 2006 Lebanon war and to a control group.

The main finding of this study is that patients during the COVID-19 outbreak waited longer before turning to hospitalization than did patients during a routine period; and the waiting in both periods was longer than during the Second Lebanon war. This finding highlights differences in patient behavior during two periods of national state of emergency. In addition, to presenting later, the COVID-19 group was in more pain than the control group, according to VAS scores. Moreover, in both the COVID-19 outbreak and the Second Lebanon war, patients were more often treated surgically than non-operatively, compared to the control group.

During the COVID-19 period, the percentage of patients presenting at the surgical department with diabetes was lower and the percentage with COPD was higher than during the other periods examined. This finding might be the result of younger and healthier patients trying to avoid the hospital during the COVID-19 outbreak, as is evident from the decline in the total number of emergency department (ED) visits during the outbreak.

The longer time from onset of symptoms to admission in the COVID-19 group can be explained by patients' concerns of contracting the virus in the ED. Accordingly, the number of admissions was lower than during the other periods. This is consistent with reports from other countries, where the number of ED visits greatly declined during lockdown. 5,6 On the other hand, the shorter time to admission in the Second Lebanon war group could be explained by a different case mix, with a higher emergency severity index. This is similar to the findings of Makhlouf-Obermeyer et al. who examined ED admissions during weeks in which a violent event occurred. ${ }^{7}$ Nevertheless, we cannot confirm this hypothesis due to the lack of data regarding the emergency severity index.

Despite the greater time to admission during the state of emergency periods, the treatment method was more aggressive than during the control group. However, other characteristics did not differ significantly between the state of emergency and the control groups, suggesting that the emergency situation affected the surgical decision making. The higher rates of comorbidities during the state of emergency periods also support this conclusion, due to the greater possibility of intraoperative and postoperative complications and the tendency to prefer non-operative treatment in such patients.

A possible explanation for the higher rates of surgical treatment during the state of emergency periods is the greater severity of the medical conditions, a parameter that we were not able to assess directly. As suggested above, it is possible that only patients who were more ill presented to the ED during the COVID19 lockdown. Though clinical parameters between patients in the lockdown period and the control period were similar, patients who presented during the COVID-19 outbreak reported higher levels of pain. The 
association between the intensity of pain and the severity of the underlying condition is well known ${ }^{8}$ and may lead a surgeon to prefer surgical treatment over non-operative treatment. As the objective parameters were similar between the periods, including age and vital signs, the state of emergency itself may have exacerbated the pain perceived by the patients. Prior research has linked anxiety state and acute pain, and recently published papers have linked the COVID-19 outbreak to a higher level anxiety. ${ }^{9-12}$ It is likely that patients during the Second Lebanon war also presented to the ED with greater pain, though data are not available.

Another possible explanation for the higher rate of surgery during the COVID-19 period is that the state of emergency itself affected decisions to perform surgery. The benefit of surgical treatment and the risk of non-operative treatment have been identified as the highest predictors of surgery. ${ }^{13,14}$ Furthermore, Szatmary et al found that surgeons with less surgical experience were more likely to assess higher nonoperative risk and thus opted to perform surgery more often. ${ }^{14}$ We speculate that the uncertainty regarding the possibility to perform surgery during the hospitalization, due to resource prioritization may have contributed to the higher rates of surgery.

This study has a number of limitations due in large part to the retrospective design. Data were not available equally for all the periods, such as the absence of pain reports during the Second Lebanon War. Moreover, hospital admissions may have been affected by differences due to the seasons of the periods assessed. Treatments may have been affected by changes in clinical practice and decision making during the 14 years that lapsed between the earliest and the latest periods.

\section{Conclusion}

In conclusion, this study shows that patients seek medical attention at a different stage of their illness in states of national emergencies, and receive different treatments than during routine periods. However, unlike in other states of national emergency, during the current COVID-19 outbreak the patients refrained from seeking early medical attention, possibly due to the perception that hospitals are a place with high risk for contracting the novel virus. This behavioral change poses risk for patients with surgical emergencies, and may lead to late morbidity and mortality.

\section{Abbreviations}

COVID-19, coronavirus disease 2019.

\section{Declarations}

Acknowledgements: Not applicable.

Authors' contributions:IAS and MB contributed to the concept of the study design, data analyses and interpretation, and manuscript critical revision. SG, RF and AM contributed to the data collection, literature 
search, data interpretation, and manuscript drafting. $A B$ and FM contributed to the statistical analysis and data interpretation. ZT and KK the literature critical review, data interpretation, and manuscript critical revision. EK drafted the work and substantively revised it.

All authors read and approved the final version of the manuscript.

Funding: Availability of data and materials The authors are responsible for the data described in the manuscript and assure full availability of the study material.

Availability of data and materials: The authors are responsible for the data described in the manuscript and assure full availability of the study material.

Ethics approval and consent to participate: The study protocol was approved by the Institutional Review Board and in accordance with the ethical principles described in the Declaration of Helsinki. Consent to participate is not applicable.

Consent for publication: Not applicable.

Competing interests: The authors declare to have no competing interest to disclose in relation to the present study.

\section{References}

1. WHO. WHO Characterizes COVID-19 as A Pandemic. World Heal Organ. 2020.

2. De Filippo O, D'Ascenzo F, Angelini F, Bocchino PP, Conrotto F, Saglietto A, et al. Reduced Rate of Hospital Admissions for ACS during Covid-19 Outbreak in Northern Italy. N Engl J Med. 2020.

3. Yeo D, Yeo C, Kaushal S, Tan G. COVID-19 and the General Surgical Department - Measures to Reduce Spread of SARS-COV-2 Among Surgeons. Ann Surg. 2020.

4. Monti S, Delvino P, Bellis E, Milanesi A, Brandolino F, Montecucco C. Impact of delayed diagnoses at the time of COVID-19: Increased rate of preventable bilateral blindness in giant cell arteritis. Ann. Rheum. Dis. 2020.

5. Thornton J. Covid-19: A\&E visits in England fall by 25\% in week after lockdown. BMJ. 2020.

6. Hartnett KP, Kite-Powell A, DeVies J, Coletta MA, Boehmer TK, Adjemian J, et al. Impact of the COVID19 Pandemic on Emergency Department Visits - United States, January 1, 2019-May 30, 2020. MMWR Morb Mortal Wkly Rep. 2020.

7. Makhlouf-Obermeyer C, Sharara E, El-Eid G, Hitti EA. Indirect impact of violent events on emergency department utilization and disease patterns. BMC Emerg Med. 2020.

8. McNamara R, Dean AJ. Approach to Acute Abdominal Pain. Emerg. Med. Clin. North Am. 2011.

9. Rajkumar RP. COVID-19 and mental health: A review of the existing literature. Asian J Psychiatr. 2020. 
10. Qiu J, Shen B, Zhao M, Wang Z, Xie B, Xu Y. A nationwide survey of psychological distress among Chinese people in the COVID-19 epidemic: Implications and policy recommendations. Gen. Psychiatry. 2020.

11. Boeke S, Duivenvoorden HJ, Verhage F, Zwaveling A. Prediction of postoperative pain and duration of hospitalization using two anxiety measures. Pain. 1991.

12. Kapoor S, White J, Thorn BE, Block P. Patients presenting to the emergency department with acute pain: The significant role of pain catastrophizing and state anxiety. Pain Med (United States). 2016.

13. Sacks GD, Dawes AJ, Ettner SL, Brook RH, Fox CR, Maggard-Gibbons M, et al. Surgeon perception of risk and benefit in the decision to operate. Ann Surg. 2016.

14. Szatmary P, Arora S, Sevdalis N. To operate or not to operate? A multi-method analysis of decisionmaking in emergency surgery. Am J Surg. 2010. 